\title{
PERFIL DE PROPRIEDADES RURAIS DO MUNICÍPIO DE JATAÍ-GO E REGIÃO E A UTILIZAÇÃO DA INSEMINAÇÃO ARTIFICIAL EM BOVINOS
}

Vinicio Araújo Nascimento ${ }^{1}$, Marcia Dias ${ }^{2}$, Lara Rodrigues de Queiros Carvalho ${ }^{3}$, Jesuíno Arvelino Pinto ${ }^{4}$, Larissa Vieira de Paula ${ }^{5}$

${ }^{1}$ Professor Doutor do Curso de Zootecnia-UFG/Regional Jataí, Jataí-GO, e do curso de Medicina Veterinária-UNIFIMES, Mineiros-GO, Brasil (e-mail: vinicioaraujon@yahoo.com.br).

${ }^{2}$ Profa Doutora do Curso de Zootecnia-UFG/Regional Jataí, Jataí-GO, Brasil.

${ }^{3}$ Zootecnista formada pela UFG/Regional Jataí, PROBEC/CNPq, Jataí-GO, Brasil.

${ }^{4}$ Graduando de Medicina Veterinária, UNIFIMES - Centro Universitário de Mineiros, Bolsista PIBIC FIMES, Mineiros, GO, Brasil.

${ }^{5}$ Graduanda de Medicina Veterinária, UFG/Regional Jataí, Jataí-GO, Brasil.

Recebido em: 08/09/2015 - Aprovado em: 14/11/2015 - Publicado em: 01/12/2015 DOI: http://dx.doi.org/10.18677/Enciclopedia_Biosfera_2015_204

\section{RESUMO}

O município de Jataí-GO detém 283.600 cabeças de bovinos e destaca-se pela terceira posição no ranking de maior produção de leite bovino do país. Objetivou-se estudar as características do sistema produtivo empregado pelos pecuaristas no município e na região de Jataí-GO com a realização de pesquisas de percepção por um questionário quali-quantitativo. Foram entrevistados 100 produtores, sendo destes 56 bovinocultores de leite e 44 de corte, do segundo semestre de 2010 ao primeiro semestre de 2015. No questionário foram abordados: atividade econômica principal, sistema de manejo, espécies criadas, grupo genético de bovinos, práticas de melhoramento genético, taxa estimada de fertilidade das fêmeas bovinas, uso de escrituração zootécnica e assistência técnica. Com relação à atividade econômica, $54,5 \%$ dos produtores dedicam-se a bovinocultura de leite e $45,5 \%$ a de corte. 0 sistema de manejo de bovinos mais utilizado é o extensivo 55,6\% e 49,5\% dos produtores criam mais de três espécies animais. Predomina a criação de bovinos sintéticos em 54,6\% ( $n=54)$. Cerca de $54,6 \%$ dos produtores não praticam melhoramento genético e $54,5 \%$ estimam a taxa de fertilidade do rebanho acima de $80 \%$. O total de $82,0 \%$ não fazem escrituração zootécnica e 56,0\% possuem assistência técnica. Nota-se que nas propriedades rurais de Jataí-GO e região o sistema de produção é de baixa produtividade, limitando assim o desenvolvimento da bovinocultura.

PALAVRAS-CHAVE: gado de corte, gado de leite, manejo, técnicas de produção

\section{CHARACTERISTICS OF THE PRODUCTIVE SYSTEM USED BY THE RANCHERS IN THE COUNTY AND REGION OF JATAÍ - GO AND THE USE ARTIFICIAL INSEMINATION IN CATTLE}

\footnotetext{
ABSTRACT

The county of Jataí has 283.600 bovines and is in the third position in the ranking of the highest bovine milk production in the country. The aim of this work was to study ENCICLOPÉDIA BIOSFERA, Centro Científico Conhecer - Goiânia, v.11 n.22; p.2329 2015
} 
the characteristics of the productive system used by the ranchers in the county and region of Jataí - GO using a research of perception through a questionnaire qualiquantitative. One hundred producers were interviewed, among them 56 dairy producers and 44 beef producers, in the second half of 2010 to the first half 2015 . In the questionnaire were asked: the main economic activity, management system, species bred, genetic group of bovines, practices of animal breeding, estimated fertility rate of the female bovines, use of the zootechnical bookkeeping and technical assistance. When it comes to the economic activity $54.5 \%$ of the producers are involved with dairy production and $45.5 \%$ with beef production. The most used management system is the extensive, $55.6 \%$ and $49.5 \%$ of the producers breed more than three animal species. The breeding of synthetic bovines is predominant in $54,6 \%(n=54)$. Around $54,6 \%$ of the producers don't do genetic breeding and $54,5 \%$ estimate a rate of fertility of the herd over $80 \%$. A total of $82.0 \%$ don't do zootechnical bookkeeping and $56.0 \%$ have technical assistance. It can be observed that in the farms in the county and region of Jataí-GO the production system is of low productivity, limiting the development of the bovinoculture though.

KEYWORDS: biotechnology, beef cattle, dairy cattle, management, production techniques

\section{INTRODUÇÃO}

O Brasil é um dos maiores produtores e exportadores de carne bovina e, também, produtor de leite. O estado de Goiás possui destacável colaboração nesta produção. A partir dos dados de 2014, o rebanho bovino brasileiro é estimado em cerca de 212.343.932 milhões de animais. Goiás ocupa a terceira colocação nacional, com 10,1\% desse efetivo. Quase um terço do rebanho brasileiro, 33,5\%, está concentrado na região Centro Oeste. No Brasil, em 2014, foram ordenhadas cerca de 23.064.495 milhões de vacas, com a produção de 35.174.271.000 bilhões de $\mathrm{kg}$ de leite e a produção média por vaca de $1.525,04 \mathrm{~kg}$. Goiás foi o segundo estado em quantidade de vacas ordenhadas, 2.658.373, o quarto em quantidade de leite produzido, 3.684.341.000 bilhões de $\mathrm{kg}$ de leite, e o nono em produção de leite por vaca, 1.385,94 kg (IBGE, 2014). Tal variação no ranking, caracteriza a necessidade de investimentos em manejo e genética pelos proprietários goianos.

O município de Jataí apresentou o total de 283.600 cabeças de bovinos no ano de 2014. Desse total, há 52.700 vacas ordenhadas, a produção total de leite de $144.700 .000 \mathrm{~kg}$, sendo a produção média por vaca de $2.745,73 \mathrm{~kg}$. Entre os anos de 2010 e 2014, houve a diminuição de 11,9\% no total de bovinos do município de Jataí, o aumento de $12,0 \%$ na quantidade de vacas ordenhadas e o crescimento da produção média de leite por vaca de $8,3 \%$ (IBGE, 2014). Em relação ao dados do Estado, a produção de leite por vaca em Jataí é bastante considerável, evidenciando a evolução no manejo e na genética dos animais em produção do município.

Para que o crescimento da produção de leite e carne se mantenham é de suma importância que os produtores invistam em tecnologias, tornando a pecuária mais competitiva e melhorando as oportunidades de negócios. Algumas tecnologias ou estratégias de manejo simples podem incrementar a pecuária brasileira, como a estação de monta, adequada relação touro:vaca, exames andrológicos, programas de acasalamento e/ou uso de Inseminação Artificial (IA).

A Inseminação Artificial é uma das biotécnicas de menor custo aplicada a campo, mas o maior entrave é a necessidade de detecção de estro. Assim, a Inseminação Artificial em Tempo Fixo (IATF) é uma estratégia de aplicação desta 
biotécnica quanto ao controle do ciclo estral pela utilização de fármacos específicos. Com isso, pode-se controlar o momento da ovulação estabelecendo o melhor horário para a inseminação artificial. A utilização da IA e/ou da IATF no estado de Goiás é de $53,5 \%$ pelos pecuaristas. Dos que utilizam a inseminação, $68,4 \%$ utilizam a IA convencional, 18,4\% associam a IA convencional com a IATF e 13,2\% utilizam exclusivamente a IATF (GORDO, 2011).

O Brasil ainda utiliza pouco a IA, resultado principalmente da má divulgação, da falta de acompanhamento profissional e investimento na especialização de mãode-obra. No ano de 2014, com cerca de 56.160.000 de fêmeas em idade reprodutiva, $11,9 \%$ foram inseminadas. Houve o decréscimo de $0,3 \%$ em relação ao ano de 2013, mas mesmo assim, desde o ano de 2011 tem-se o crescimento da quantidade de matrizes inseminadas, ultrapassando o patamar de $10 \%$. Isto indica que novos clientes aderiram à técnica e que os produtores tradicionais ampliaram a utilização. Entre os anos de 2009 a 2014, maior evolução foi para o gado de corte, $59 \%$, em relação ao gado de leite, 34\%. O estado de Goiás encontra-se em 3ํlugar, $11 \%$, dentre os estados brasileiros com maior participação em vendas de sêmen de bovinos de corte, após os estados de MT e MS. Na participação em vendas de sêmen de bovinos de leite, está em 5 lugar, com o índice de 7\%, seguindo os estados de MG, RS, PR e SC (ASBIA, 2014).

Assim, com o presente trabalho objetivou-se estudar o perfil de propriedades rurais do município Jataí - GO e região e o uso da Inseminação Artificial em bovinos.

\section{MATERIAL E MÉTODOS}

Foi realizada uma pesquisa, na qual se utilizou uma amostragem não probabilística, utilizando um questionário com perguntas de aspectos qualitativos e quantitativos. Foram entrevistados 100 bovinocultores atuantes na produção de leite (56 bovinocultores de leite) elou na produção de carne (44 bovinocultores de corte) no município de Jataí - GO e região (Mineiros, Caçu, Caiapônia, Perolândia, Rio Verde, Serranópolis). A veracidade das informações foi creditada aos próprios bovinocultores, visto que não foram confirmadas, e houveram questões não respondidas, diferenciando no total em algumas análises.

No questionário foram abordados componentes biodemográficos (idade, tempo de experiência na atividade pecuária, grau de escolaridade, utilização de estação de monta, uso de IA, tamanho da propriedade e principais fontes de renda da família). As entrevistas foram realizadas do segundo semestre de 2010 ao primeiro semestre de 2015 pelos alunos de Medicina Veterinária e Agronomia da Universidade Federal de Goiás Regional Jataí e pelos alunos de Medicina Veterinária do Centro Universitário de Mineiros - UNIFIMES.

Os entrevistados foram classificados quanto à idade nas seguintes faixas etárias: 18 a 24 (proprietários jovens), 25 a 64 (proprietários adultos) e acima de 65 anos (proprietários idosos). Em relação ao grau de escolaridade, foram divididos em primeiro grau completo ou incompleto, segundo grau completo ou incompleto e superior e pós graduação. Quanto a experiência na atividade agropecuária, foram classificados de acordo com o período dedicado a mesma $(0-10,11-20$, e acima de 20 anos).

As propriedades foram classificadas em pequena, média e grande, de acordo com o módulo fiscal do município de Jataí - GO (Instituto Nacional de Colonização e Reforma Agrária - INCRA, 2003). Em relação às instalações das propriedades, a 
classificação foi em precárias (curral descoberto e tronco coletivo), boas (currais cobertos, tronco coletivo e/ou brete de contenção individual) e adequadas para a realização da IA (currais cobertos, tronco coletivo, brete de contenção individual, balança, cômodo para o material de inseminação e pia com água corrente) (Manual de Inseminação Artificial em Bovinos, 2013). Na avaliação das condições para o bem-estar animal, as propriedades foram classificadas em fraca, média e boa, de acordo com presença de sombreamento natural e/ou artificial.

As propriedades foram distintas pela atividade principal, em bovinocultura de leite ou de corte; e, pelos sistemas de manejo dos bovinos, em extensivo, semi intensivo e intensivo. Verificou-se, também, a presença de outras espécies animais nas propriedades (bubalinos, caprinos, ovinos, suínos, equinos e aves).

Os bovinos criados nas propriedades foram identificados pelo grupo genético predominante (Bos taurus taurus continentais, Bos taurus taurus britânicos, Bos taurus indicus, sintéticos, adaptados e compostos). Os proprietários foram também questionados quanto a aplicação prática do melhoramento genético dos bovinos e aos dados de fertilidade das fêmeas. Na verificação do uso da biotecnologia IA, os produtores foram questionados se a adotavam ou se apenas utilizavam a monta natural. Juntamente, foi verificado se a IA era realizada em associação com a estratégia de manejo estação de monta.

Após a aplicação dos questionários, os dados foram tabulados e analisados por estatística descritiva. Foram analisadas as distribuições de frequências relativas das respostas para a descrição dos resultados. Realizou-se a correlação de Spearman para verificar as relações entre algumas variáveis: uso da Inseminação Artificial; grau de escolaridade, idade e experiência dedicada a atividade econômica principal dos proprietários; tamanho da área da propriedade; infraestrutura da mesma para o uso da biotécnica e assistência técnica nas fazendas. Todas as análises foram realizadas com o auxílio do programa SAS v.9.2 (2008) a 5\% de probabilidade.

\section{RESULTADOS E DISCUSSÃO}

A maioria dos entrevistados $(n=100)$ estava na faixa etária de 25 a 64 anos, classe adulta (75,0\%). Quanto ao grau de escolaridade dos produtores, foi observada certa homogeneidade na distribuição em relação às formações de primeiro grau completo e incompleto, segundo grau completo e incompleto e superior e pós-graduação (Tabela 1). Pode-se, assim, observar que são produtores com acesso a informações e com competência gestora para investir na produtividade da pecuária, o que demonstra a evolução educacional dos produtores rurais corroborando com ALVES (2006).

TABELA 1. Idade, grau de escolaridade e experiência na atividade dos entrevistados de Jataí - GO e região

\begin{tabular}{cccccr}
\hline \multicolumn{2}{c}{ Idade $(\mathrm{n}=100)$} & \multicolumn{2}{c}{ Grau de escolaridade $(\mathrm{n}=100)$} & \multicolumn{2}{c}{ Experiência na } \\
Anos & $(\%)$ & Grau & $(\%)$ & Anos & $(\%)$ \\
\hline 18 a 24 & 4,0 & $\begin{array}{c}\text { Primeiro grau completo e } \\
\text { incompleto }\end{array}$ & 23,0 & $\mathbf{0 - 1 0}$ & 28,0 \\
25 a 64 & 75,0 & $\begin{array}{c}\text { Segundo grau completo e } \\
\text { incompleto }\end{array}$ & 40,0 & $11-20$ & 33,0 \\
$>$ 65 & 21,0 & Superior e pós-graduação & 37,0 & $>20$ & 39,0 \\
\hline
\end{tabular}


Foi observado que a maioria dos proprietários entrevistados tinha experiência a mais de 10 anos na atividade $(72,00 \%$; Tabela 1$)$. Assim, a atividade para maioria dos proprietários era algo que está plenamente inserida no dia a dia dos mesmos. Por um lado, isso facilita a aplicação de novas tecnologias, embora em contrapartida, há certos produtores que se mantem fiéis à forma de produção de períodos anteriores, se negando à aplicação de biotecnologias, destacando a IA. GORDO (2011) encontrou resultados semelhantes em relação a experiência na atividade, em que também $72,0 \%$ possuíam experiência na pecuária há mais de 9 anos.

Pelos dados foi demonstrado que a maior parte dos 100 entrevistados possuíam o tamanho de área entre 160 a 600 hectares $(40,0 \%)$, ou seja, o meio rural é composto principalmente por propriedades de tamanho médio no município de Jataí e região. Um percentual de $28,0 \%$ das propriedades são pequenas (Tabela 2). Sabe-se que o uso da IA em pequenas propriedades é mais fácil de ser aplicado devido à facilidade em manejar o rebanho quanto a detecção de estro.

A maioria dos entrevistados $(n=100)$ relatou possuir instalações inadequadas $(50,0 \%)$ para um manejo respeitando o bem-estar animal. De certa forma, compromete-se a utilização de biotecnologias. Apenas $21,0 \%$ dos proprietários assumiram terem instalações adequadas para o uso de biotecnologias, destacando a IA. Nessas situações, eram observadas que as instalações do meio rural podem comprometer a difusão da biotécnica, visto que o sucesso da atividade necessita de instalações apropriadas que garantam o bem-estar animal e, também, acomodação do material de trabalho e dos técnicos.

TABELA 2. Tamanho da área, condições das instalações para realização da Inseminação Artificial e ambiência das propriedades dos entrevistados de Jataí - GO e região

\begin{tabular}{cccccc}
\hline \multicolumn{2}{c}{ Tamanho da área $^{1}(\mathbf{n}=\mathbf{1 0 0})$} & \multicolumn{2}{c}{ Instalações $(\mathbf{n}=\mathbf{1 0 0})^{2}$ Ambiência $^{2}(\mathbf{n}=\mathbf{9 8})$} \\
\hline Há & $(\%)$ & Instalações & $(\%)$ & Nível & $(\%)$ \\
\hline $\mathbf{0}-\mathbf{1 6 0}$ & 28,0 & Inadequadas & 50,0 & Fraca & 17,3 \\
$\mathbf{1 6 0}-\mathbf{6 0 0}$ & 40,0 & Boas & 29,0 & Média & 32,7 \\
$>\mathbf{6 0 0}$ & 32,0 & Adequadas & 21,0 & Boa & 50,0
\end{tabular}

'Classificação do tamanho das áreas com base nos módulos fiscais do município de Jatai-GO. Fonte: Instituto Nacional de Colonização e Reforma Agrária - INCRA, 2003.

${ }^{2} \mathrm{~A}$ ambiência foi avaliada pelas condições oferecidas nas propriedades relativas ao sombreamento.

Foi observado que $82,7 \%$ dos proprietários se preocupam com as condições de ambiência ou bem estar, visto que nas propriedades havia condições para o conforto animal referentes a presença de árvores e/ou de sombrite (Tabela 2). O que é um fator positivo para a eficiência reprodutiva dos animais submetidos a IA. O ambiente, destacando o clima, exerce muito efeito na produtividade, influenciando o comportamento animal e a produção, influenciado negativamente pelo estresse térmico, pois, o bem estar animal refere-se ao animal que está com liberdade psicológica (de não estar exposto a medo, ansiedade ou estresse), liberdade comportamental (de expressar seu comportamento normal), liberdade fisiológica (de não sentir fome ou sede), liberdade sanitária (de não estar exposto a doenças, ENCICLOPÉDIA BIOSFERA, Centro Científico Conhecer - Goiânia, v.11 n.22; p.2333 2015 
injúrias ou dor) e liberdade ambiental (de viver em ambientes adequados, com conforto) (NÄÄS, 2004).

Entre os proprietários entrevistados, $54,5 \%$ dedicam-se a bovinocultura de leite e 45,5\% a de corte (Tabela 3). O município de Jataí, desde o ano de 2010 está crescendo em produção de leite no país (IBGE, 2014), o que pode ser consequência do maior investimento dos produtores de leite comparado aos de carne em tecnologias e, também, pelo município ser o maior produtor de grãos do estado, possibilitando o uso insumos na pecuária leiteira a custos mais acessíveis.

TABELA 3. Atividade principal, sistemas de manejo e espécies criadas nas propriedades dos entrevistados de Jataí - GO e região

\begin{tabular}{|c|c|c|c|c|c|}
\hline \multicolumn{2}{|c|}{ Atividade principal $(n=99)$} & \multicolumn{2}{|c|}{$\begin{array}{c}\text { Sistemas de manejo } \\
(n=99)\end{array}$} & \multicolumn{2}{|c|}{$\begin{array}{c}\text { Espécies criadas } \\
(n=99)\end{array}$} \\
\hline Atividade & $(\%)$ & Sistema & $(\%)$ & $\begin{array}{l}\text { Número de } \\
\text { espécies }\end{array}$ & $(\%)$ \\
\hline Leite & 54,5 & Extensivo & 57,6 & $\begin{array}{l}\text { Somente } \\
\text { bovinos }\end{array}$ & 14,1 \\
\hline \multirow[t]{3}{*}{ Corte } & 45,5 & $\begin{array}{c}\text { Semi- } \\
\text { intensivo }\end{array}$ & 39,4 & $\begin{array}{c}\text { Bovinos + } 1 \\
\text { espécie }\end{array}$ & 21,2 \\
\hline & & Intensivo & 3,0 & $\begin{array}{c}\text { Bovinos }+2 \\
\text { espécies }\end{array}$ & 15,2 \\
\hline & & & & >3 espécies & 49,5 \\
\hline
\end{tabular}

Das propriedades em que a atividade econômica principal era a exploração leiteira $(n=54), 53,7 \%$ não possuíam outra atividade, $24,1 \%$ exerciam a criação de bovinos de corte, 16,2\% praticavam a agricultura e 5,6\% outras atividades. Das propriedades em que a atividade econômica principal era a exploração de gado de corte $(n=45), 68,9 \%$ não possuíam outra atividade, $20,0 \%$ praticavam a agricultura e $11,1 \%$ outras atividades (Tabela 3 ). Em trabalho realizado por AZEVEDO et al., (2011), na região norte de Minas Gerais, foi relatado que de 47 propriedades avaliadas, 21 produtores atuavam simultaneamente nos setores de leite e de corte e 26 produziam somente leite, indicando uma característica que pode causar dificuldade para se definir um padrão de produção de leite ou de corte.

No Brasil, existem três tipos principais de sistemas de manejo de bovinos. $O$ sistema extensivo é caracterizado pela utilização de pastagens nativas e cultivadas como únicas fontes de alimentos, com suplementação ou não de mineral. O sistema semi-intensivo é caracterizado pelo uso de pastagens (nativas e cultivadas ou pastejo rotacionado) e suplementos minerais, acrescidos de suplementos protéicos/energéticos com objetivo de alcançar uma pecuária de ciclo mais curto. Já os sistemas intensivos caracterizam-se pela prática de confinamento com a utilização de ração total (EMBRAPA, 2005). Em Jataí e região, o sistema de manejo mais utilizado foi o extensivo com $57,6 \%$ dos entrevistados. Havia menor dedicação a bovinocultura em sistema intensivo (Tabela 3). Assim, o emprego da IA era dificultado na região, visto que para a aplicação desta biotécnica há necessidade de maior manejo com os animais, sendo facilitada em criações mais intensivas. 
Foi observado entre os bovinocultores que $14,1 \%$ criavam apenas bovinos, $21,2 \%$ criavam mais uma espécie animal, 15,2\% mais duas espécies e 49,5\% criavam três ou mais espécies de animais (Tabela 3). Notou-se, então, uma variedade de culturas existentes nas propriedades. Deduz-se que essa variedade de criações refere-se a meios diferentes para o consumo doméstico ou uma segunda fonte de renda.

No estado de Goiás, há relato de que $29,7 \%$ dos pecuaristas obtém renda exclusiva da pecuária, $16,2 \%$ sustentam suas respectivas famílias associando a pecuária com a agricultura e, apenas, 9,5\% dos pecuaristas obtém renda com a criação de gado, a agricultura e também praticando outra atividade (GORDO, 2011). Mesmo observando várias fontes de renda, verifica-se que a maior parte advém do meio rural. A partir disso, percebe-se a consciência dos produtores em diversificar os meios de produção para tentar garantir maior sustentabilidade ou dinâmica na atividade rural. Embora, tenha-se que observar que, quando o produtor cria várias espécies na mesma propriedade, há exigência de maior controle para cada criação, a fim de evitar perdas econômicas por falhas na gestão de uma das atividades.

Entre os bovinos da região, o grupo genético em maior quantidade eram os sintéticos (mestiços) com 54,5\%, seguido pelos Bos taurus indicus (Nelore) com $38,4 \%$ e pelos Bos taurus taurus (Holandês) com 7,1\% (Tabela 4). AZEVEDO et al. (2011) justificam a maior prevalência de animais mestiços zebuínos na produção de leite no norte de Minas Gerais pela opção de animais mais rústicos e resistentes aos diversos problemas encontrados na região, como o clima e as infestações parasitárias. Estes mesmos fatores podem estar relacionados a maior criação de animais mestiços em Jataí e região.

TABELA 4. Grupo genético de animais, práticas de melhoramento genético e taxa estimada de fecundidade das fêmeas nas propriedades dos entrevistados de Jataí - GO e região

\begin{tabular}{cccccc}
\hline $\begin{array}{c}\text { Grupo } \\
\text { genético } \\
(\mathbf{n}=99)\end{array}$ & $(\%)$ & $\begin{array}{c}\text { Melhoramento } \\
(97)\end{array}$ & $(\%)$ & $\begin{array}{c}\text { Fecundidade } \\
\text { das fêmeas } \\
(\mathbf{n}=99)\end{array}$ & $(\%)$ \\
\hline $\begin{array}{c}\text { Bos taurus } \\
\text { taurus }\end{array}$ & 7,1 & Não pratica & 54,6 & $<60$ & 2,0 \\
$\begin{array}{c}\text { Bos taurus } \\
\text { indicus }\end{array}$ & 38,4 & $\begin{array}{c}\text { Touros e } \\
\text { matrizes } \\
\text { selecionados } \\
\text { Seleção na } \\
\text { compra de } \\
\text { sêmen }\end{array}$ & 41,2 & $60-80$ & 43,4 \\
\hline
\end{tabular}

Em Jataí e região, a porcentagem de produtores que não praticavam melhoramento na propriedade era de $54,6 \%$. Há certo prejuízo para o desempenho da bovinocultura, visto que o melhoramento genético baseia-se na seleção de indivíduos com maior desenvolvimento ponderal, rendimento de carcaça, produção leiteira, melhor conversão alimentar e precocidade sexual, possibilitando o aumento da produtividade tanto de carne quanto de leite (INFORZATO, 2008). O índice de $41,2 \%$ dos proprietários afirmaram realizar o melhoramento genético com base no 
uso de touros e matrizes selecionadas. Enquanto, apenas 4,2\% dos produtores se preocupavam com o uso de sêmen de touros provados.

Os proprietários foram também questionados sobre a fecundidade das fêmeas. Cerca de 54,6\% responderam que a fertilidade das vacas é satisfatória com fertilidade acima de $80 \%$. Rebanhos com fertilidade entre 60 e $80 \%$ foram relatados por $43,4 \%$ dos produtores. Já $2,0 \%$ assumiram possuir rebanhos com fecundidade inferior a 60\%. Na região Centro-oeste, a taxa de natalidade está em cerca de $69 \%$ (ANUALPEC, 2011). Pelos dados da pesquisa, os produtores de Jataí e região relataram taxa de natalidade maior, embora tenha sido constatado haver deficiência de escrituração zootécnica dos rebanhos, gerando certa desconfiança quanto a veracidade dessas informações.

Quanto a assistência técnica, dentre as 100 propriedades analisadas, 44,0\% não possuíam e 56,0\% possuíam. A falta de acompanhamento técnico, muitas vezes, reduz o potencial produtivo da propriedade, diminuindo a produtividade, a lucratividade e a competitividade da atividade pecuária. Muitos produtores argumentaram que não fazem uso da assistência técnica por não haver necessidade.

A necessidade de produzir mais e de realizar a modernização do setor somente será alcançada com a dedicação dos produtores rurais de se associarem à políticas sérias, que proporcionem a evolução do setor, sendo acompanhada com assistência técnica qualificada.

A utilização de escrituração zootécnica nas propriedades foi baixa, 82,0\% não faziam e 18,0\% faziam. O uso de escrituração zootécnica com abordagens produtiva, reprodutiva, sanitária, alimentar e outras, é útil para o descarte de animais de baixa produção, alimentação dos animais de acordo com a produção, avaliação de estratégias de manejo, análise de eficiência reprodutiva do rebanho, além das avaliações genéticas dos animais. Tais registros possibilitam ao produtor, melhor gerência do seu sistema de produção, permitindo-lhe alcançar melhorias na produtividade do rebanho.

A utilização de inseminação pelos pecuaristas de Jataí e região é baixa (Tabela 5). Apenas $24,2 \%$ dos produtores fazem uso desta biotécnica, a qual é de menor custo, eficiente no melhoramento genético do rebanho, controla doenças venéreas, registra a reprodução de forma precisa, garante a gestão da propriedade e segurança dos funcionários (HAFEZ, 2004). Na região, cerca de $88,8 \%$ dos entrevistados utilizam monta natural. Embora os custos operacionais da IA, em alguns casos, sejam superiores à monta natural, o resultado final será sempre favorável devido ao ganho genético incorporado ao rebanho. Ao utilizar o touro provado pela $I A$, metade de seu valor genético é transmitido para a progênie, aumentando o potencial genético do rebanho.

TABELA 5. Utilização da biotécnica Inseminação Artificial, monta natural e da estratégia estação de monta nas propriedades dos entrevistados de Jataí - GO e região

\begin{tabular}{cccccc}
\hline $\begin{array}{c}\text { Inseminação } \\
\text { Artificial (n=95) }\end{array}$ & $(\%)$ & $\begin{array}{c}\text { Monta } \\
\text { natural } \\
(\mathbf{n = 7 2 )}\end{array}$ & $(\%)$ & $\begin{array}{c}\text { Estação } \\
\text { de monta } \\
(\mathbf{n}=95)\end{array}$ & $(\%)$ \\
\hline Sim & 24,2 & Sim & 88,8 & Sim & 10,5 \\
Não & 75,8 & Não & 11,2 & Não & 89,5 \\
\hline
\end{tabular}


Somente $10,5 \%$ dos pecuaristas utilizavam a estação de monta (EM). O objetivo principal da estação de monta é aumentar a eficiência reprodutiva proporcionando um sincronismo entre período de maior requerimento nutricional da vaca, que é o período de lactação com o período de maior oferta de alimento, o período das chuvas, alcançando melhores índices reprodutivos. A utilização da estação de monta é viável para aproveitar o preço do mercado dos bovinos e as pastagens em quantidade e qualidade.

Em análise dos proprietários que realizam a Inseminação Artificial $(n=23)$, $78,3 \%$ tinham como atividade econômica principal a leiteira, enquanto que $21,7 \%$ era a de corte. Nas propriedades em que era realizada a IA $(n=23)$, quinze produtores responderam outras questões relativas à biotécnica, sendo que desses, $86,7 \%(n=13)$ utilizavam rufião, 33,3\% ( $n=5)$ utilizavam rufião com buçal marcador e $6,7 \%(n=1)$ realizavam somente a observação visual do estro sem a presença de rufião. $O$ uso de rufião junto às fêmeas tem como vantagens estimular a ciclicidade das fêmeas, acelerar a puberdade nas novilhas, diminuir o anestro pós-parto em vacas, aumentar o tempo de manifestação de estro, induzir sinais de estro mais evidentes e sincronizar melhor a ovulação. Um dos grandes desafios da IA é a detecção de estro e com a utilização do rufião com o buçal marcador este desafio pode diminuir.

Das propriedades que realizavam a monta natural $(n=64), 87,5 \%$ utilizavam touro em conjunto com as vacas e $12,5 \%$ utilizavam touro em monta controlada. A presença do touro dificulta a realização das escriturações zootécnicas por não haver o controle da data de cobertura e nem previsão de parto, o que dificulta 0 melhoramento genético do rebanho.

Foi realizada correlação de Spearman das variáveis quanto ao uso da Inseminação Artificial; ao grau de escolaridade, idade e experiência dedicada a atividade econômica principal dos proprietários; ao tamanho da área da propriedade; a infraestrutura da mesma para o uso da biotécnica e assistência técnica nas fazendas. Houve correlação positiva $(P<0,05)$ para assistência técnica e instalações $(r=0,3548)$, assim, julga-se que quando se faz uso de assistência técnica há maior investimento do proprietário em instalações, devido ao acesso a informações sobre as vantagens, preços e variedades. Idade e experiência $(r=0,3200)$ também apresentaram correlação positiva $(P<0,05)$, ou seja, quanto maior a idade maior a experiência, consequentemente maior o entendimento sobre a atividade e maior a facilidade de se inserir novas tecnologias.

A correlação da idade e do grau de escolaridade $(r=-0,3920)$ foi negativa $(P<0,05)$, significando que quanto maior a idade menor o grau de escolaridade, demonstrando que em períodos passados existia menor procura e oportunidade para profissionalização. Estas correlações se fazem importantes por interferirem na aplicação da IA, pois a assistência técnica influencia no investimento de infraestrutura, que é fator indispensável para conseguir bons índices com a biotecnologia, e a experiência na atividade relacionada com a idade influencia a procura de assistência técnica.

Com tais contribuições para o desenvolvimento da pecuária brasileira, a IA impulsiona de maneira significativa a produtividade de carne e de carcaças de qualidade pelo maior valor genético dos reprodutores. Para a produção de leite, a IA pode gerar forte impacto na pequena propriedade rural, desenvolvendo e agregando valor para matrizes. Com isso, o pequeno produtor não precisa manter touros na 
propriedade e tem condições de investir mais em matrizes de maior produção por área (MARTINS et al., 2009; SOUZA, 2011).

\section{CONCLUSÕES}

O perfil das propriedades rurais de Jataí - GO e região são similares ao encontrado no estado de Goiás.

Os produtores de gado de corte ou de leite estão ainda engajados em sistemas de produção com baixa produtividade, alguns desconhecendo até mesmo a realidade de suas propriedades.

O uso da biotécnica Inseminação Artificial é baixo pelos produtores do município de Jataí-GO e região, demonstrando a necessidade de divulgação dos programas de IA existentes ou até de novas biotecnologias, a fim de aumentar a produtividade da bovinocultura da região.

\section{REFERÊNCIAS}

ALVES, E. Migração rural-urbana, agricultura familiar e novas tecnologias: coletânea de artigos revistos. Brasília, DF: Embrapa Informação Tecnológica, 2006. $181 \mathrm{p}$.

ANUÁRIO DA PECUÁRIA BRASILEIRA. Anualpec 2011. São Paulo: Instituto FNP, 2011. 190p.

ASBIA. INDEX ASBIA - Mercado de sêmen 2014. Uberaba - MG: Associação Brasileira de Inseminação Artificial. Disponível em: http://www.asbia.org.br/novo/upload/mercado/index2014.pdf. Acesso em: 20 de outubro de 2015.

AZEVEDO, R.A.; FELIX, T.M.; PIRES JÚNIOR, O.S.; ALMEIDA, A.C.; DUARTE, E.R. et al. Perfil de propriedades leiteiras ou com produção mista no norte de Minas Gerais. Revista Caatinga, v.24, n.1, p.153-159, 2011.

EMBRAPA Gado de Leite. Sistema de Produção, n.7. 2005. ISSN 1678-314X. Disponível em: http://sistemasdeproducao.cnptia.embrapa.br/FontesHTML/Leite/LeiteRecriadeNovil has/instalacoes.html. Acesso em: 20 de outubro de 2015.

GORDO, J.M.L. Análise da situação da Inseminação Artificial bovina no estado de Goiás. Goiânia: Universidade Federal de Goiás, p107. Tese (Doutorado em Ciência Animal) Universidade Federal de Goiás, 2011.

HAFEZ, E.S.E. Reprodução animal. 7.ed. São Paulo: Manole, 582p., 2004.

IBGE. Goiás. Pecuária 2014. Disponível em: http://www.ibge.gov.br/estadosat/temas.php?sigla=go\&tema=pecuaria2014. Acesso em: 25 de outubro de 2015. 
INCRA. INSTITUTO NACIONAL DE COLONIZAÇÃO E REFORMA AGRÁRIA. Imóveis rurais cadastrados no INCRA, segundo os municípios. Posição outubro/2003. Disponível em: www.semarhtemplat.go.gov.br/uploads/files/gbio/car/modulos fiscais.htm. Acessado em: 10 de agosto de 2013.

INFORZATO, G.R.; SANTOS, W.R.M.; CLIMENI, B.S.O.; DELLALIBERA, F.L.; FILADELPHO, A.L. Emprego de IATF (inseminação artificial em tempo fixo) como alternativa na reprodução da pecuária de corte. Revista Científica Eletrônica de Medicina Veterinária, n.11, p.1-8, 2008.

Manual de Inseminação Artificial em Bovinos. Associação Brasileira de Inseminação Artificial (ASBIA). Disponível em: www.asbia.org.br. Acesso em: 10 de Agosto de 2013.

MARTINS, C.F.; SIQUEIRA, L.G.B.; OLIVEIRA, C.T.S.A.M.; SCHWARZ, D.G.G.; OLIVEIRA, F.A.S.A.M. Inseminação artificial: uma tecnologia para o grande e pequeno produtor. Planaltina, DF. 2009,33 p. Embrapa Cerrados, Documentos 261.

NÄÄS, I.A. Novos conceitos de ambiência na produção intensiva de animais. In: III Congresso Nordestino de Produção Animal, 2004. Campina Grande. Anais... Campina Grande, 2004.

SAS. SAS/STAT User's Guide (Release 9.2), SAS Inst., Inc., Cary, NC. 2008.

SOUZA, A.B. Inseminação Artificial em bovinos: um instrumento para o desenvolvimento rural. 2011. 44f. Monografia (Tecnólogo em Planejamento e Gestão para o Desenvolvimento Rural) - Faculdade de Ciências Econômicas da UFRGS, Canguçu, 2011. 